\title{
Atmospheric Processing of Iron-bearing Mineral-Dust Aerosol and its Effect on Growth of a Marine Diatom, Cyclotella meneghiniana
}

Eshani Hettiarachchi ${ }^{1}$, Sergei Ivanov ${ }^{2}$, Thomas Kieft ${ }^{3}$, Harland L. Goldstein ${ }^{4}$, Bruce M.

Moskowitz ${ }^{5}$, Richard L. Reynolds ${ }^{4,5}, \&$ Gayan Rubasinghege ${ }^{1^{*}}$

${ }^{1}$ Department of Chemistry, New Mexico Institute of Mining and Technology, Socorro, NM, 87801 USA

${ }^{2}$ Center for Integrated Nanotechnologies, Los Alamos National Laboratory, Los Alamos, NM, 87545 USA

${ }^{3}$ Department of Biology, New Mexico Institute of Mining and Technology, Socorro, NM, 87801 USA

${ }^{4}$ U.S. Geological Survey, Geosciences and Environmental Change Science Center, Denver, Colorado 80225 USA

${ }^{5}$ Institute for Rock Magnetism, Department of Earth and Environmental Sciences, University of Minnesota, Minneapolis, MN 55455 USA 
Table S1: The modified Aquil* medium used in diatom growth experiments

\begin{tabular}{|c|c|c|c|}
\hline \multicolumn{4}{|c|}{ Modification of Aquil* Medium } \\
\hline Method & \multicolumn{3}{|c|}{ All water should be Milli-Q water, sterilized accordingly. } \\
\hline $\begin{array}{l}600 \mathrm{~mL} \text {, } \\
\text { dissolve } \\
\text { anhydrous salts }\end{array}$ & & & \\
\hline $\begin{array}{l}300 \mathrm{~mL} \text {, } \\
\text { dissolve hydrous } \\
\text { salts }\end{array}$ & & \multicolumn{2}{|c|}{$\begin{array}{l}\text { No extra Fe is added to make it } F e \\
\text { limiting }\end{array}$} \\
\hline \multicolumn{4}{|l|}{ combine } \\
\hline \multirow[t]{3}{*}{ add } & $\begin{array}{l}1 \mathrm{~mL} \text { of each of major nutrients stock } \\
\text { solutions }\end{array}$ & & \\
\hline & $1 \mathrm{~mL}$ of trace metal solution & & \\
\hline & $1 \mathrm{~mL}$ of vitamin solutions & & \\
\hline \multicolumn{4}{|l|}{ bring up to $1 \mathrm{~L}$} \\
\hline \multirow[t]{3}{*}{ Then Add } & $\begin{array}{l}3.34 \mathrm{~mL} \text { of the Silicate Solution } \\
\text { (Major Nutrient Stock) }\end{array}$ & \multirow{3}{*}{\multicolumn{2}{|c|}{ The modification for diatoms }} \\
\hline & $\begin{array}{l}3.34 \mathrm{~mL} \text { of a } 0.001 \mathrm{M} \mathrm{FeCl}_{3} .6 \mathrm{H} 2 \mathrm{O} \\
\text { Solution }\end{array}$ & & \\
\hline & $1.5 \mathrm{~mL}$ of $1 \mathrm{M} \mathrm{NH}_{4} \mathrm{Cl}$ Solution & & \\
\hline \multicolumn{4}{|c|}{ sterilize in microwave oven/ filter sterilize Do NOT Autoclave } \\
\hline & & & \\
\hline Compound & stock solution $(\mathrm{g} / \mathrm{L})$ & $\begin{array}{l}\text { Quantity } \\
\text { used (g) }\end{array}$ & $\begin{array}{l}\text { Quantity used in } \\
\text { final solution }(\mathrm{g} / \mathrm{L})\end{array}$ \\
\hline \multicolumn{4}{|c|}{ Synthetic Ocean Water } \\
\hline \multicolumn{4}{|c|}{ Anhydrous salts: dissolve in $600 \mathrm{~mL}$ of miliQ water } \\
\hline $\mathrm{NaCl}$ & $\mathrm{NA}$ & 24.540 & 24.540 \\
\hline $\mathrm{Na}_{2} \mathrm{SO}_{4}$ & NA & 4.090 & 4.090 \\
\hline $\mathrm{KCl}$ & NA & 0.700 & 0.700 \\
\hline $\mathrm{NaHCO}_{3}$ & NA & 0.200 & 0.200 \\
\hline $\mathrm{KBr}$ & NA & 0.100 & 0.100 \\
\hline $\mathrm{H}_{3} \mathrm{BO}_{3}$ & NA & 0.003 & 0.003 \\
\hline $\mathrm{NaF}$ & NA & 0.003 & 0.003 \\
\hline \multicolumn{4}{|c|}{ Hydrous Salts: Dissolve in $300 \mathrm{~mL}$ of milliQ water } \\
\hline $\mathrm{MgCl}_{2} \cdot 6 \mathrm{H}_{2} \mathrm{O}$ & NA & 11.100 & 11.100 \\
\hline $\mathrm{CaCl}_{2} \cdot 2 \mathrm{H}_{2} \mathrm{O}$ & NA & 1.540 & 1.540 \\
\hline $\mathrm{SrCl}_{2} \cdot 6 \mathrm{H}_{2} \mathrm{O}$ & NA & 0.017 & 0.017 \\
\hline
\end{tabular}




\begin{tabular}{|l|r|r|r|}
\hline \multicolumn{3}{|c|}{ Major Nutrients Stocks: Mix 1 mL of each solution and volume up to $1 \mathrm{~L}$ to obtain a } \\
major nutrient solution
\end{tabular}

\section{Cleaning and Preparation of Dialysis Tubes for Experiments}

The dialysis tubes were tied with double knots and cleaned thoroughly following the sigmaAldrich cleaning procedure. Briefly the dialysis tubes have been first cleaned with sodium sulfide solution at $80 \square \mathrm{C}$ for $1 \mathrm{~min}$, followed by hot water at $60 \square \mathrm{C}$ for $2 \mathrm{~min}$, followed by acidification with $0.2 \%(\mathrm{v} / \mathrm{v})$ sulfuric acid and lastly, rinsing with hot water for $5 \mathrm{~min}$. Then the dialysis tubes were cleaned with running milliQ water for 5 mins. After that, the dialysis tubes were tested for Fe leaching with milliQ water and fresh mineral dust proxies (hematite and ilmenite). No Fe 
leaching has detected in the solution. Then, a few drops of $\mathrm{Fe}^{3+}$ solution was added inside the dialysis tubes and allowed to equilibrate. Then, tested for Fe leaching to the solution outside the dialysis tube. Solution contained detectable amount of $\mathrm{Fe}^{3+}$ suggesting that the tube is not a barrier for dissolved $\mathrm{Fe}$.

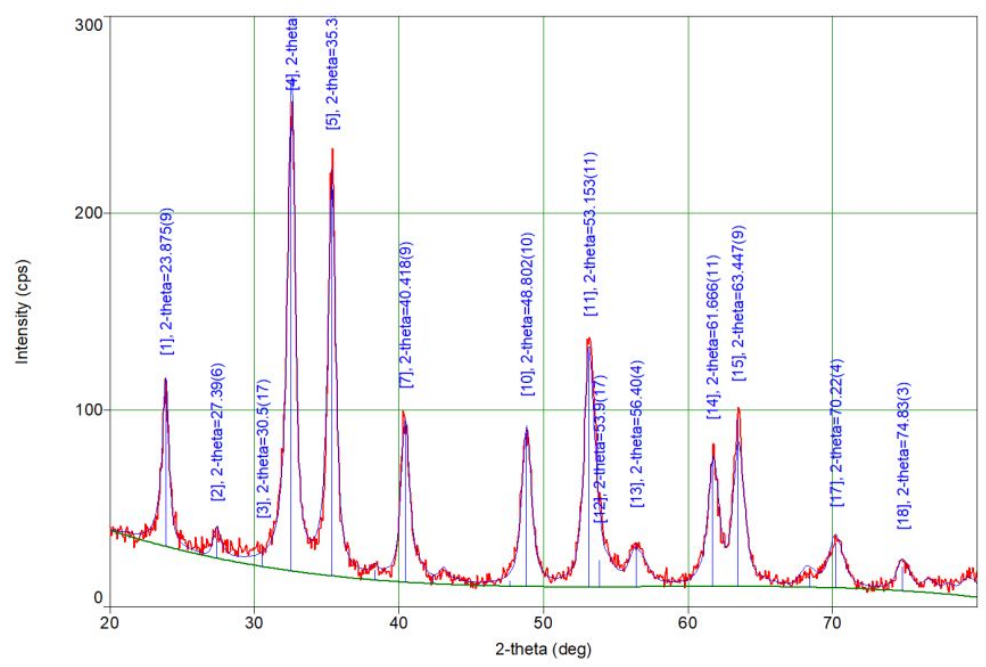

Figure S1: XRD Pattern of synthesized nano ilmenite 


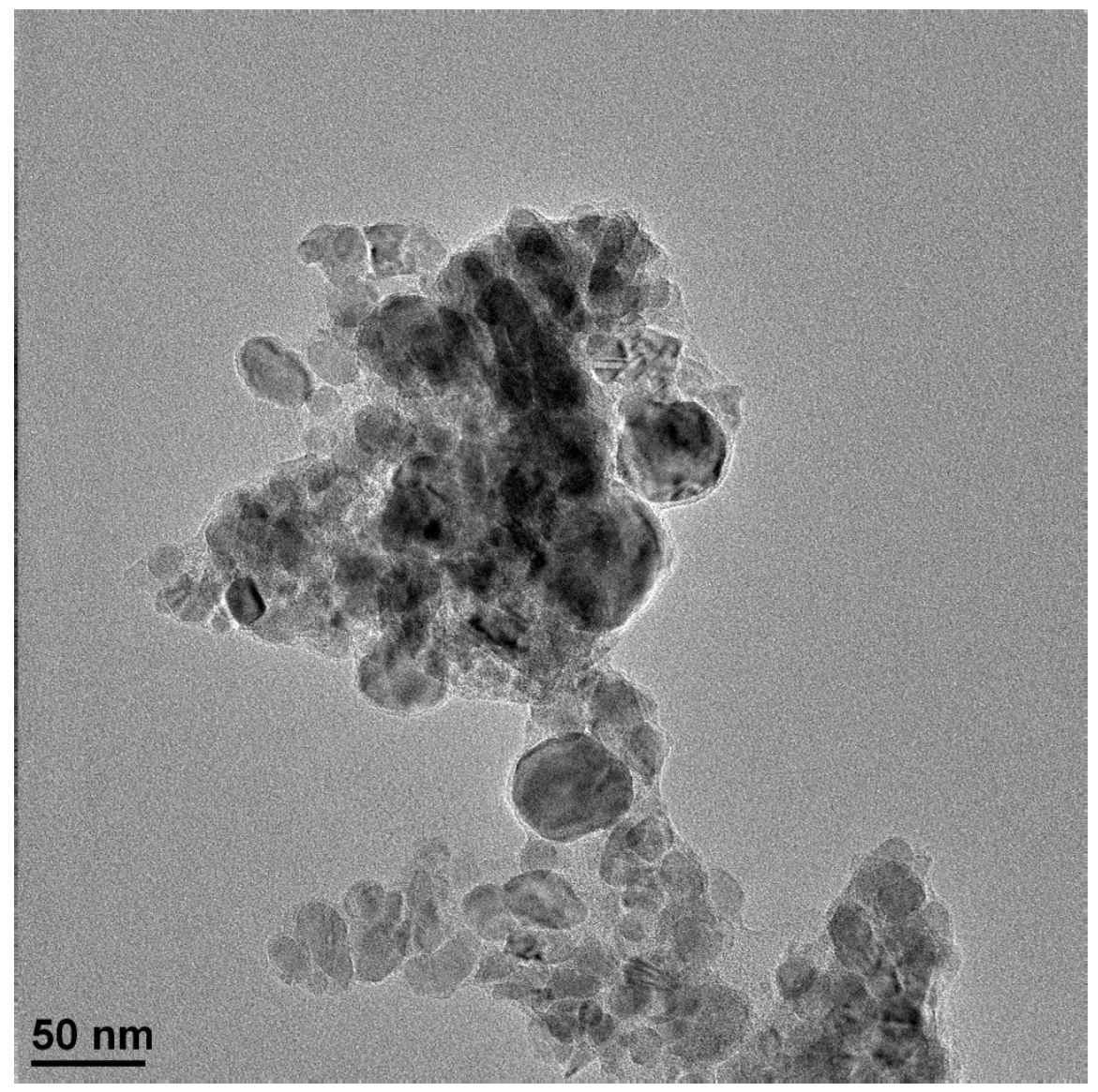

Figure S2: TEM image of nano ilmenite

\section{Particle Characterization}

The shape and size of mineral particles were determined from single-particle analysis with a scanning electron microscope (SEM) and transmission electron microscope (TEM). The size distribution was determined by analyzing 200 particles using the software package ImageJ. Surface areas of mineral samples were measured in a seven-point $\mathrm{N}_{2}$-Brunauer-Emmet-Teller (BET) surface-area analyzer. In BET analysis, the samples were outgassed overnight $(\sim 24 \mathrm{~h})$ at a temperature of $105^{\circ} \mathrm{C}$ prior to the BET analysis. 


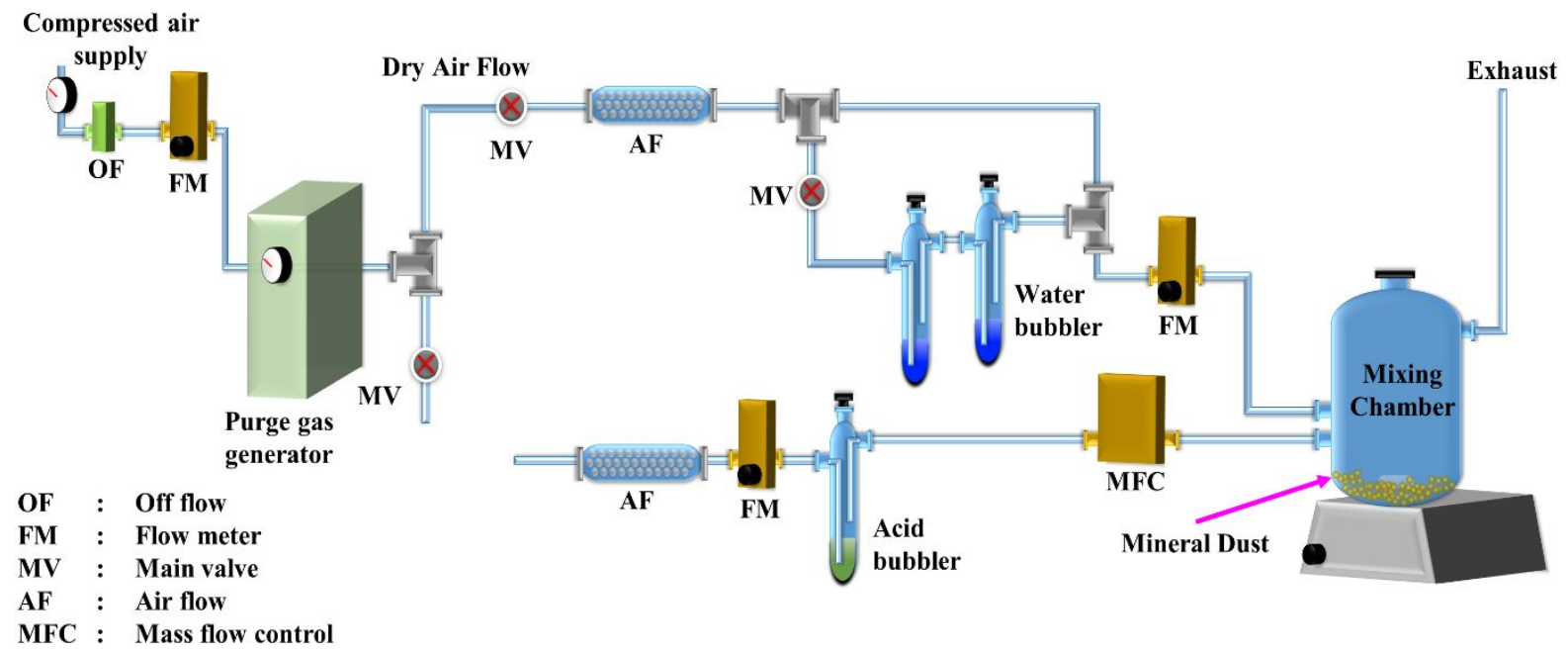

Figure S3: Custom-built flow-cell system used in simulated atmospheric processing of mineral dust aerosol

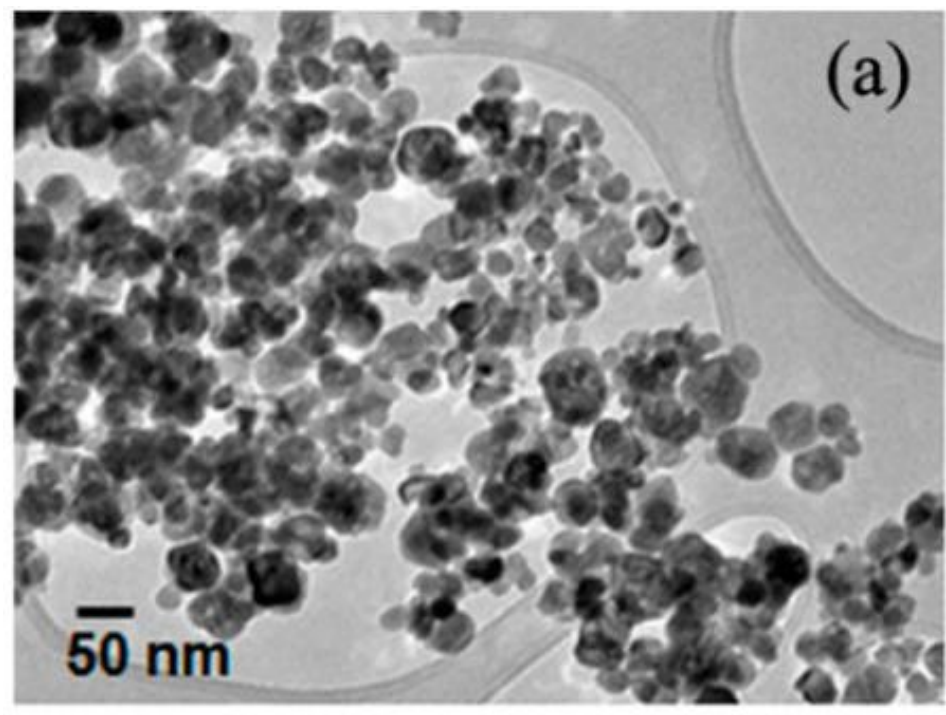

Figure S4: TEM image of Hematite ${ }^{1}$ 


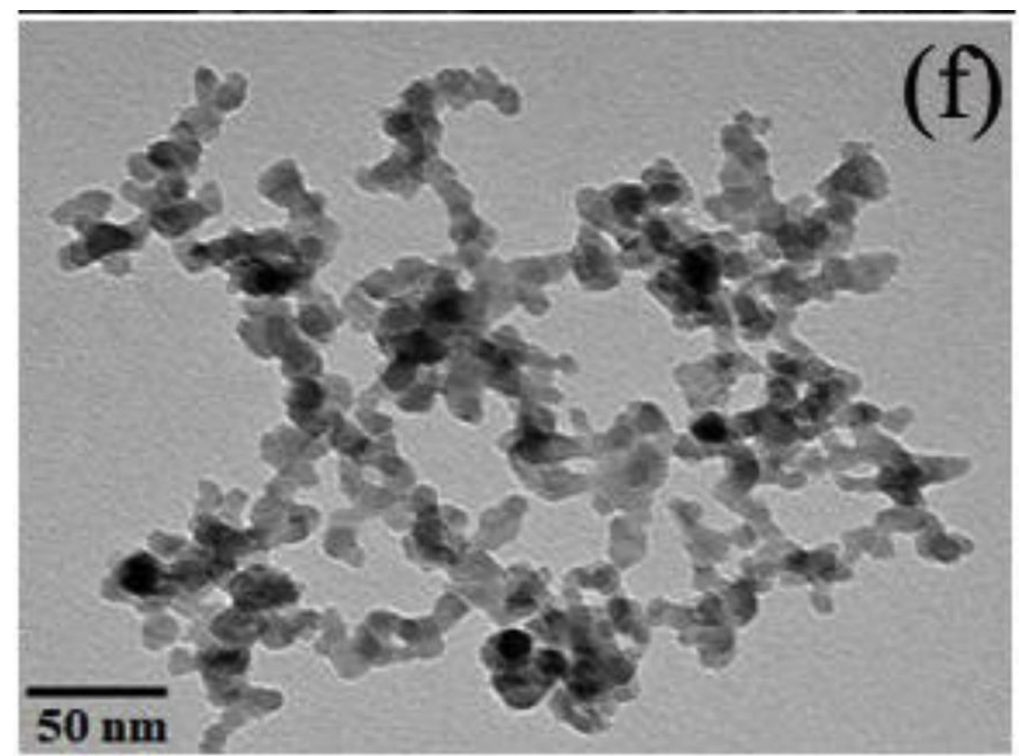

Figure S5: TEM image of Anatase ${ }^{2}$

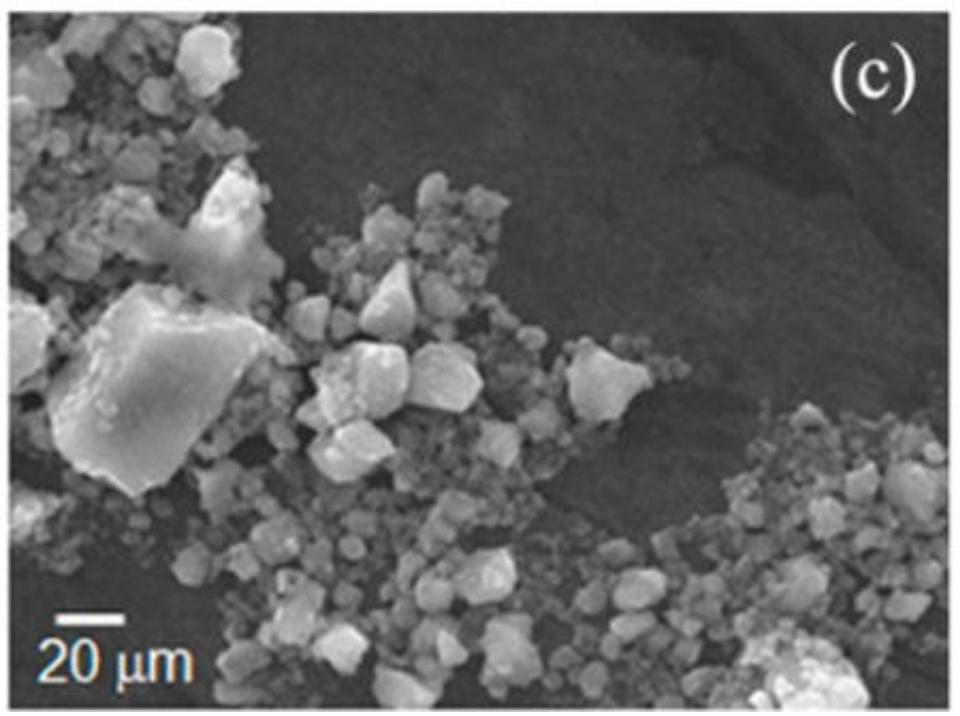

Figure S6: SEM image of micro ilmenite ${ }^{1}$ 


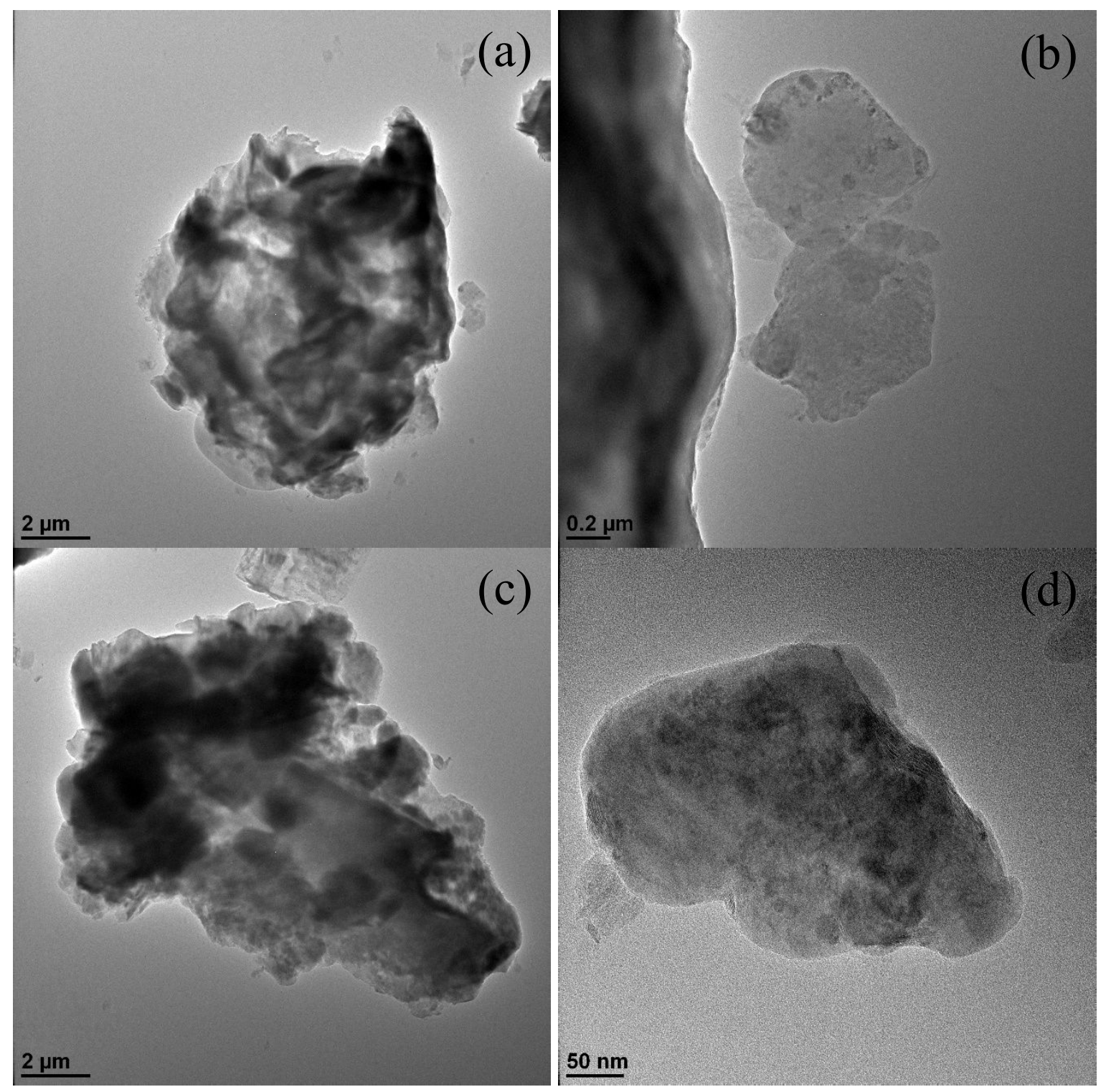

Figure S7: TEM images of (a) and (b) SZ1 and (c) and (d) RO 


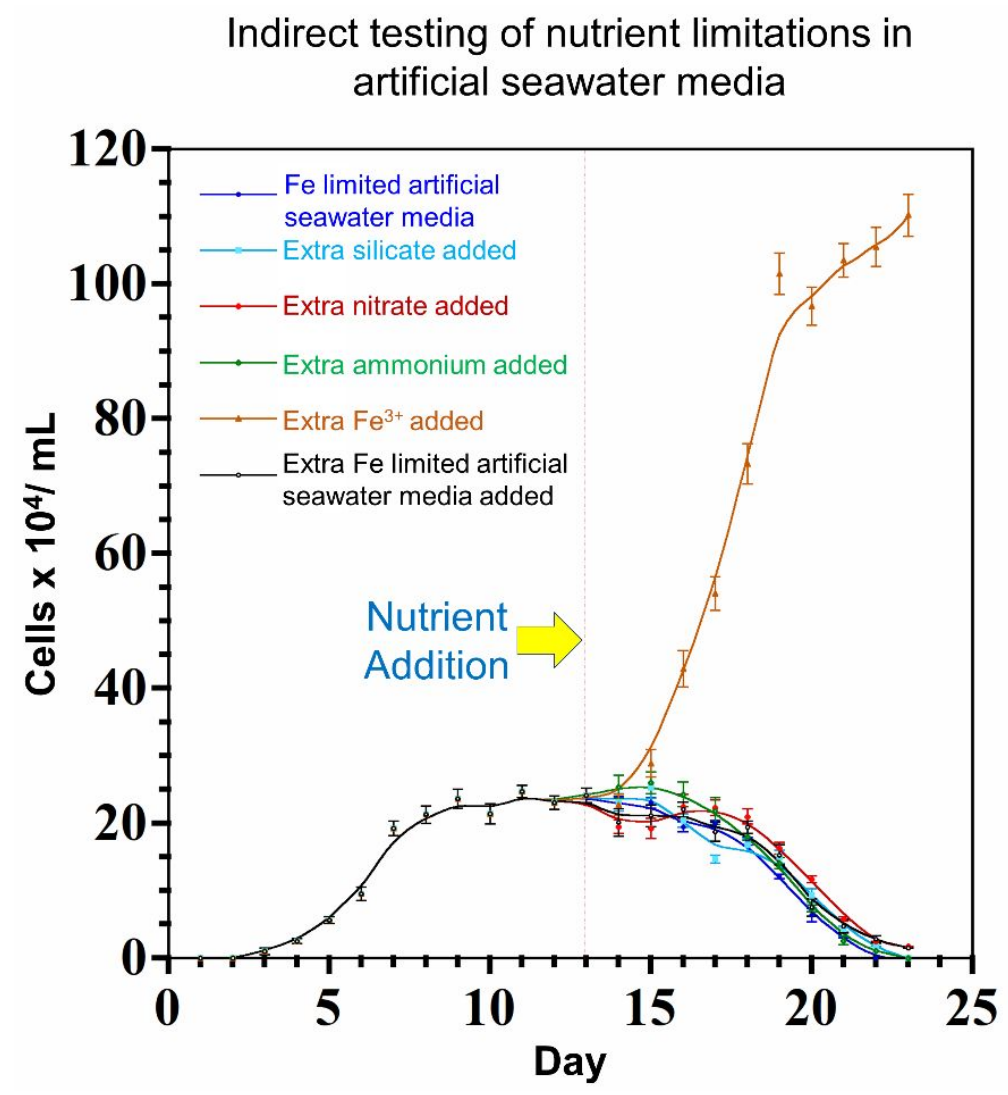

Figure S 8: Cell counts from each culture as a function of time. The diatoms were growing in a one big flask until day 13, and later separated into different cultures upon addition of different nutrients. Data fitted into smooth curve fitting to elaborate the shape of growth curves.

Fe Solubility Capacity in the Atmosphere

\section{Experimental Method:}

\section{Determination of Fe Solubility Capacity}

Batch reactor studies were carried out to simulate iron leaching from aerosol dust particles in the presence of an acid deliquescence layer where the $\mathrm{pH}$ could be as low as 1 or $2 .{ }^{3,4}$ As previously reported, the conditions in the acidic deliquescence layer were simulated in custom-built glass reactors. $^{2-7}$ The reaction vessel has a suspension capacity of $100 \mathrm{~mL}$ and a removable air-tight top. In both natural dust and proxies, the particle loading was $0.2 \mathrm{~g} / \mathrm{L}$ of mineral dust in nitric acid 
solutions at $\mathrm{pH} 2$. In the experiment with dust proxies, hematite was mixed with a non-ironcontaining metal oxide, anatase, to investigate the $\mathrm{Fe}$ solubility of hematite in the presence of $\mathrm{TiO}_{2}$. The acid solution was aerated and agitated constantly to mimic the mixing in the deliquescence layer. These experiments were performed in 8 hours/16 hours of night/ day time cycle, simulated using a solar simulator (150 W xenon lamp, Newport Corp Sol1A ABB) kept in otherwise a dark chamber. A quartz window $\left(12.5 \mathrm{~cm}^{2}\right)$ mounted on the top of the reaction vessel permitted light entry during the solar experiments. During the night time simulations, the solar simulator was turned off. The glass reactor is also equipped with a temperature probe, a standardized $\mathrm{pH}$ electrode, and a conductivity probe to measure these parameters throughout the dissolution experiment. The temperature was kept constant at $25^{\circ} \mathrm{C}$ using a water jacket. The suspended samples were periodically removed from the reactor using a disposable syringe that was connected to $12 \mathrm{~cm}$ of Teflon tubing. The collected samples were filtered through $0.2 \mu \mathrm{m}$ pore size filters and analyzed using the 1,10-phenanthroline method. ${ }^{8}$ Before filtration, the samples were centrifuged to ensure no particles in the filtrate. Control experiments verified that no dissolved iron originated from the acid solution or anatase.

\section{Results and Discussion}

The selected mineral-dust proxies and the natural dust samples were first evaluated for their atmospheric Fe-solubility capacity in the presence of gaseous $\mathrm{HNO}_{3}$ in the atmosphere. The extents of the dissolution of total $\mathrm{Fe}$, as well as dissolved Fe(II) at the end of 48 hours, are provided in Figure S9. The extents of total Fe dissolutions for both mineral dust proxies and natural dust depended on many factors such as the particle size, temperature, $\mathrm{pH}$, relative humidity as well as their mineralogy. $1,2,6,9$ The initial rates of the total Fe dissolution for hematite, hematite with $\mathrm{TiO}_{2}$,

nano ilmenite, and micro ilmenite were $82 \pm 3 \mu \mathrm{M} \mathrm{g}^{-1} \mathrm{~h}^{-1}, 79 \pm 3 \mu \mathrm{M} \mathrm{g}^{-1} \mathrm{~h}^{-1}, 92 \pm 5 \mu \mathrm{M} \mathrm{g}^{-1} \mathrm{~h}^{-1}$ and 
$21 \pm 1 \mu \mathrm{M} \mathrm{g}^{-1} \mathrm{~h}^{-1}$ respectively. Those of SZ1 and RO were $82 \pm 2 \mu \mathrm{M} \mathrm{g}^{-1} \mathrm{~h}^{-1}$ and $16 \pm 4 \mu \mathrm{M} \mathrm{g}^{-1} \mathrm{~h}^{-1}$ respectively. As shown in Figure S9(b), the total Fe solubility of hematite was 1.2\% and hematite with $\mathrm{TiO}_{2}$ was $2.8 \%$. This difference represents a $35 \%$ increment of total $\mathrm{Fe}$ dissolution when $\mathrm{TiO}_{2}$ is introduced to the system. The difference in the extent of the dissolution of hematite with and without $\mathrm{TiO}_{2}$ is statistically significant with $\mathrm{p}<0.05$. The total $\mathrm{Fe}$ solubility from nano ilmenite is $3.1 \%$, suggesting the enhancement of Fe dissolution due to mineralogical differences. Similar trends between hematite and ilmenite have been seen in our previous studies where the dissolution of ilmenite under atmospherically relevant conditions was higher than that either of hematite or maghemite. ${ }^{1}$ However, due to having a very low surface area compared to respect to other particles used in the study, the $\%$ total Fe solubility of micro ilmenite was $0.9 \%$. Similar to Fe mineral dust proxies, the natural dust sample SZ1 with comparatively higher \% Ti had higher total Fe dissolution 19.7\% compared to the RO dust (7.7\%). The natural dust samples had higher iron solubilities compared to the mineral dust proxies due to several reasons such as mineralogical and compositional complexity, the extent of weathering, and the high stability of pure mineral oxides.

Enhancement of total Fe dissolution when Ti is present in the mineral dust has been observed in our previous work. ${ }^{1,2,10,11}$ However, in these previous studies, the experimental conditions were maintained either to be oxygenated or deoxygenated and under either dark or solar irradiated conditions. These settings facilitated interpretations about mineralogy-dependent Fe dissolution at the molecular-level. In contrast to those settings, this study employed experimental conditions closer to actual environmental conditions (aerated system with day/ night $16 \mathrm{~h} / 8 \mathrm{~h}$ cycle) thereby better comparing the environmental systems. Regardless of these modifications to the experimental conditions, the results showing enhanced total $\mathrm{Fe}$ dissolution and $\mathrm{Fe}(\mathrm{II})$ production from hematite as seen in the presence of $\mathrm{TiO}_{2}$, are consistent with the previous studies. ${ }^{11}$ Briefly, 
this can be attributed to the formation of $\mathrm{H}_{2} \mathrm{O}_{2}$ from $\mathrm{HO}^{*}$ radicals generated via the adsorbed water on $\mathrm{TiO}_{2}$ or from the dissolved $\mathrm{O}_{2}$, which can reduce surface $\mathrm{Fe}(\mathrm{III})$ atoms. ${ }^{11-13}$ 

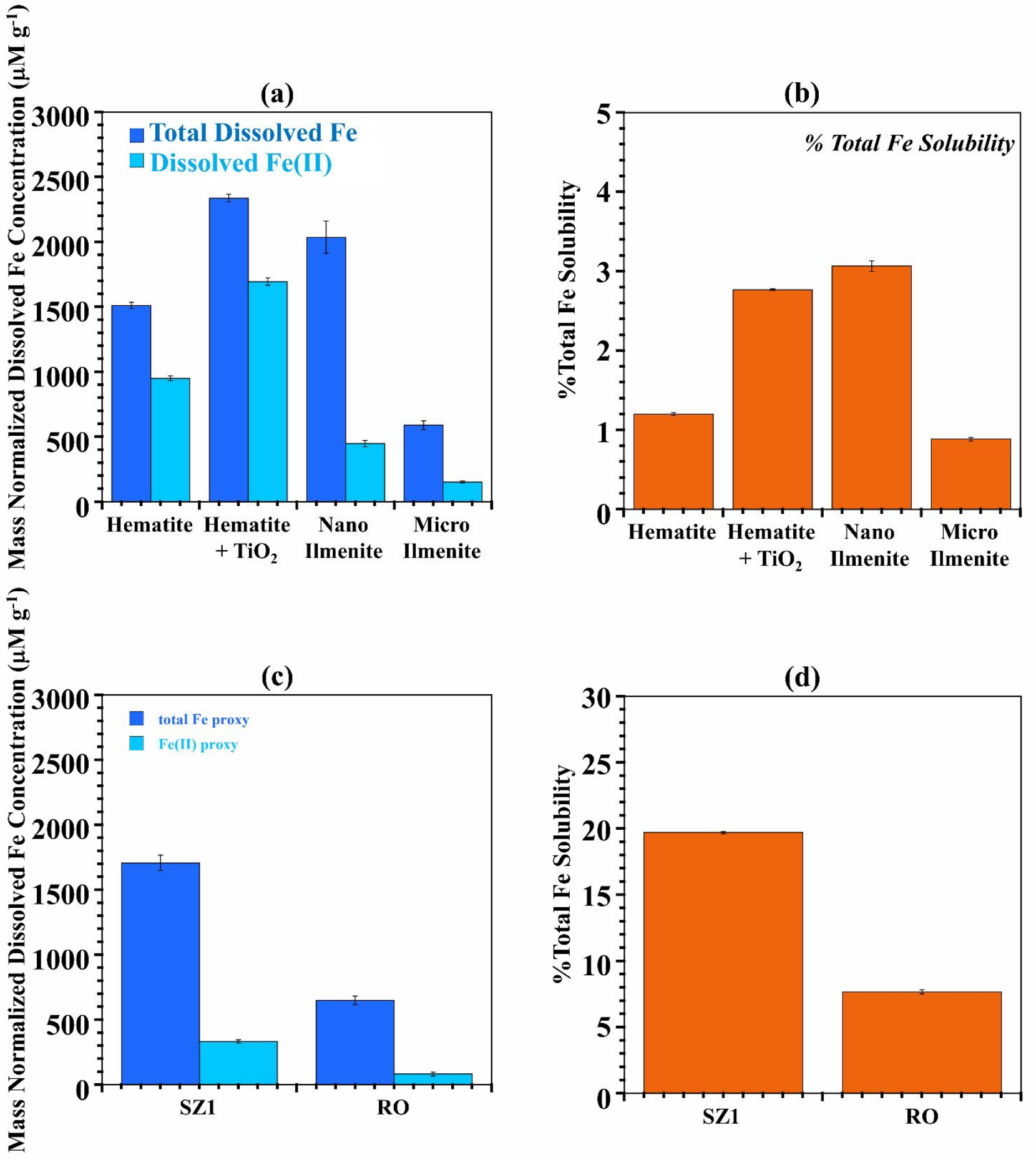

Figure S9: Mass normalized total Fe dissolution (a) mineral-dust proxies (c) natural dust and \% total Fe solubility (b) proxies (d) natural dust at the 48th hour of the reaction with aerated $\mathrm{HNO}_{3}$ with initial $\mathrm{pH}$ of 2 . 

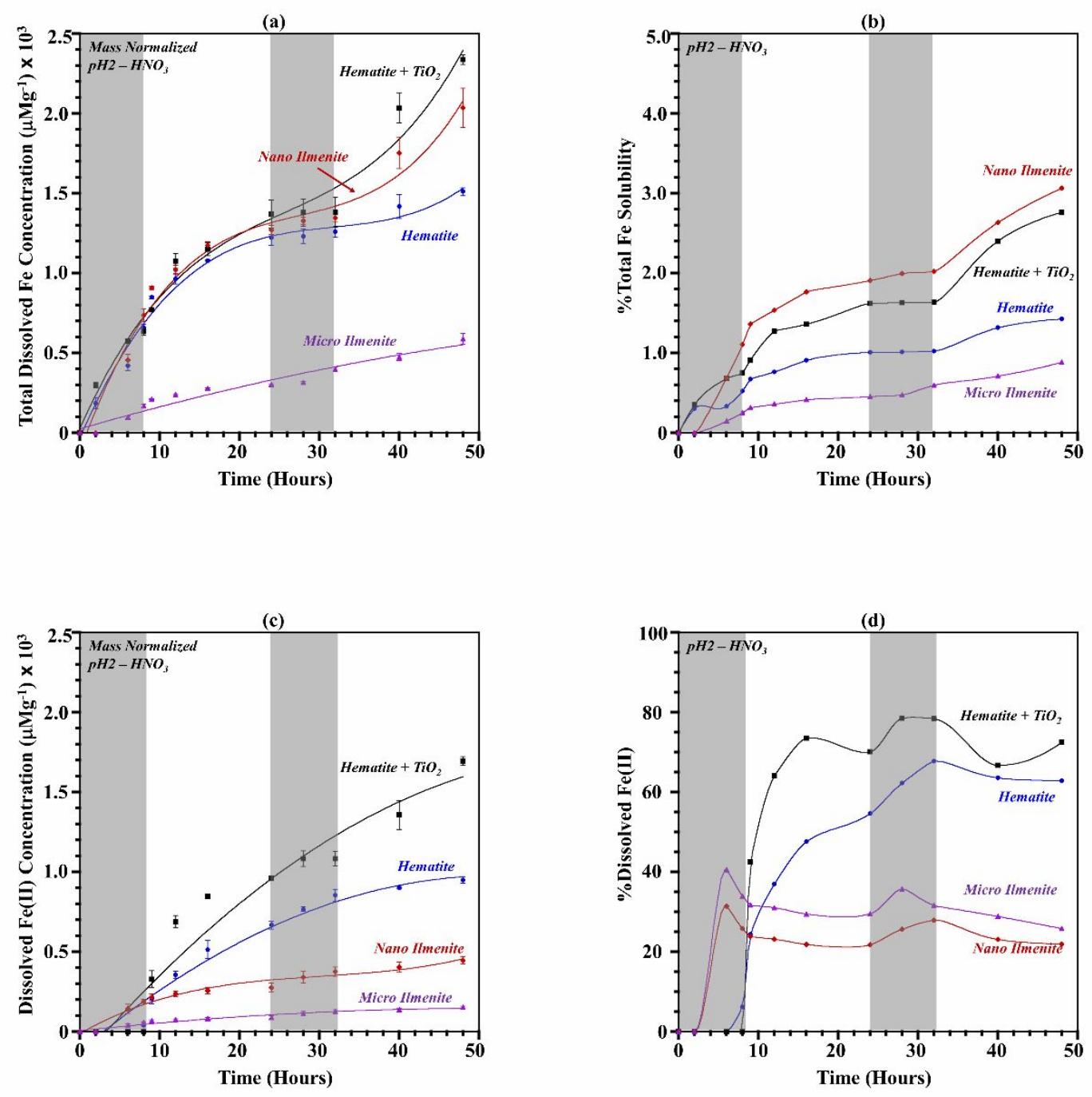

Figure S10: The dissolved Fe concentrations for hematite, hematite with $\mathrm{TiO}_{2}$, nano ilmenite, and micro ilmenite in nitric acid where the initial $\mathrm{pH}$ is 2 . (a) total dissolved $\mathrm{Fe}$, (b) \% total $\mathrm{Fe}$ solubility, (c) dissolved Fe(II) concentration, (d) \% dissolved Fe(II). The shaded area represents the dark condition and lighter areas represent the solar simulated condition. 

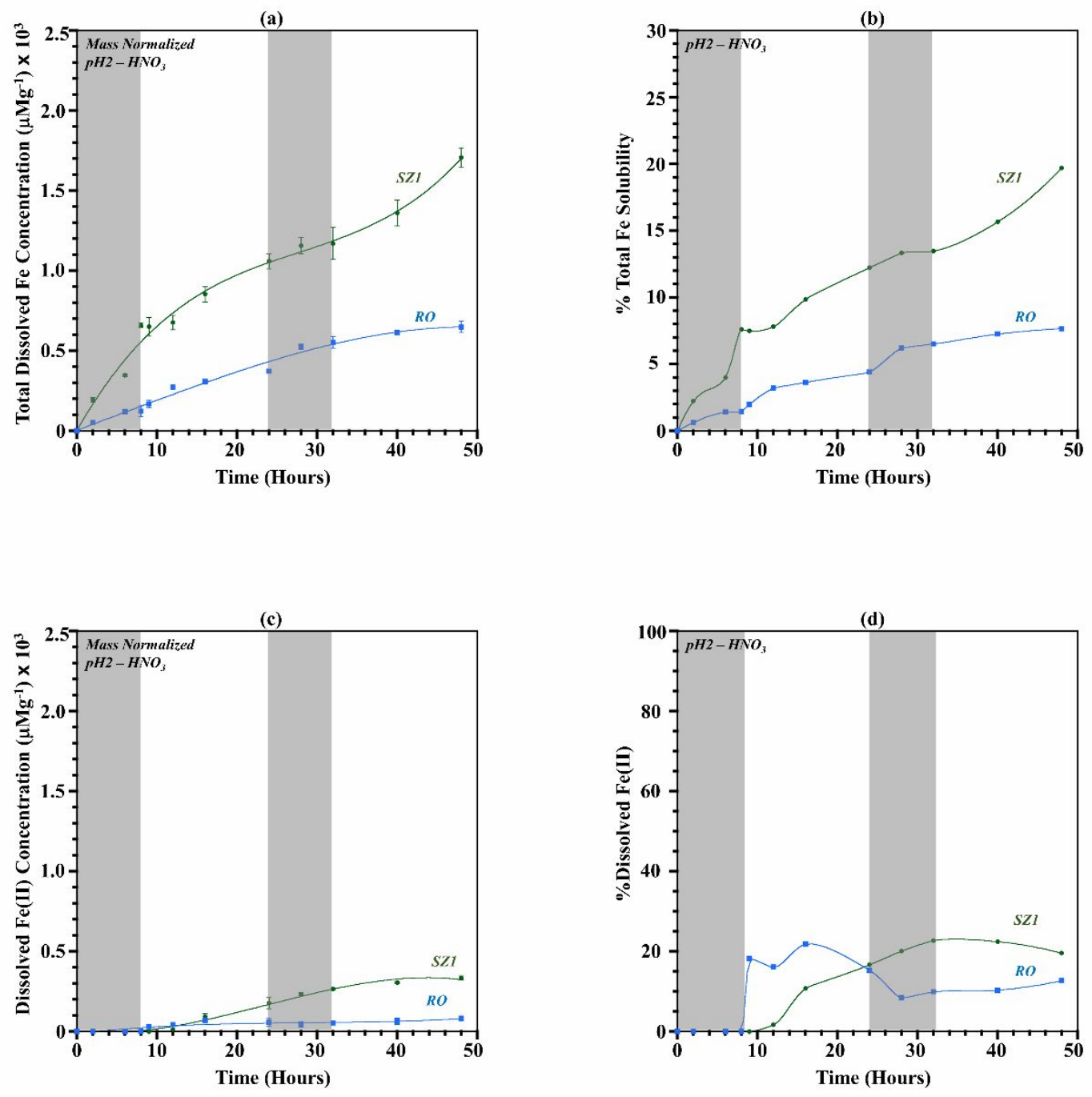

Figure S11: The dissolved Fe concentrations for SZ1 and RO in the nitric acid where the initial $\mathrm{pH}$ is 2. (a) total dissolved Fe, (b) \% total Fe solubility, (c) dissolved Fe(II) concentration, (d) \%dissolved Fe(II). The shaded area represents the dark condition and lighter areas represent the solar-simulated condition. 


\section{DFe Measured in Natural Dust Samples}

Similar to mineral-dust proxies, the DFe concentrations measured on Day 08 in natural-dusttreated inoculums with diatoms were higher than their respective diatom-absent systems.

Table S2: Measured DFe in Natural dust treated system

\begin{tabular}{|lcccc|}
\hline \multicolumn{1}{|c}{ Sample } & \multicolumn{2}{c}{ Diatoms Present $(\mu \mathbf{M})$} & \multicolumn{2}{c|}{ Diatoms Absent $(\mu \mathbf{M})$} \\
\hline & Fresh & Processed & Fresh & Processed \\
SZ1 & $0.9 \pm 0.2$ & $1.9 \pm 0.3$ & $0.3 \pm 0.1$ & below detection \\
& & & & limit \\
RO & $1.3 \pm 0.1$ & $1.8 \pm 0.3$ & $0.5 \pm 0.2$ & below detection \\
& & & & limit \\
\hline
\end{tabular}


$\mathrm{F}=$ Fresh, $\mathrm{P}=$ Processed, $\mathrm{Ini}=$ before adding to seawater, $\mathrm{ND}=$ No diatoms present, $\mathrm{D}=$ Diatoms present
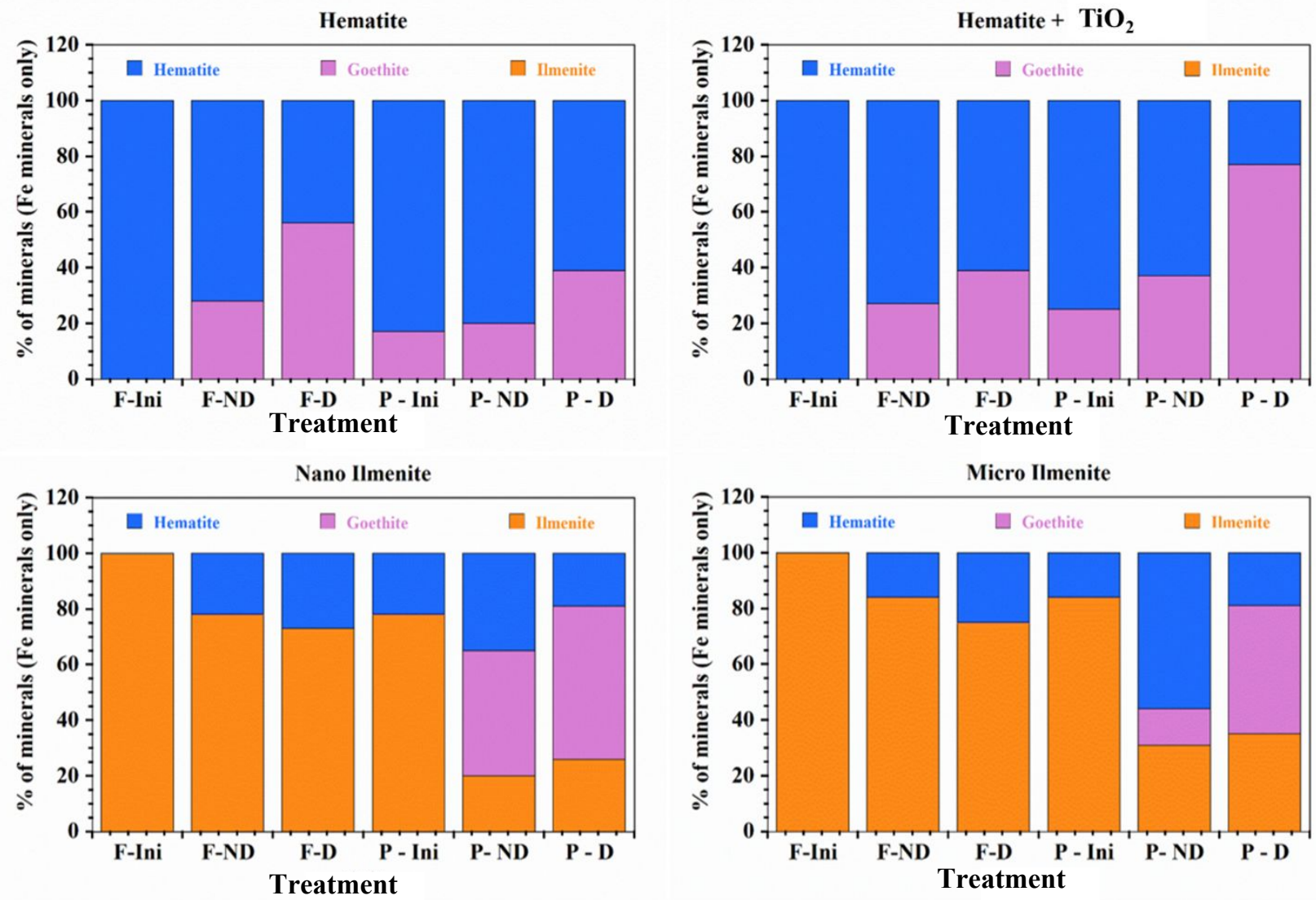

Figure S12: Mineralogical composition of Fe mineralogy of samples before and after treating with seawater both in the presence and absence of diatoms, as identified by XRD

Table S3: Total chlorophyll concentrations

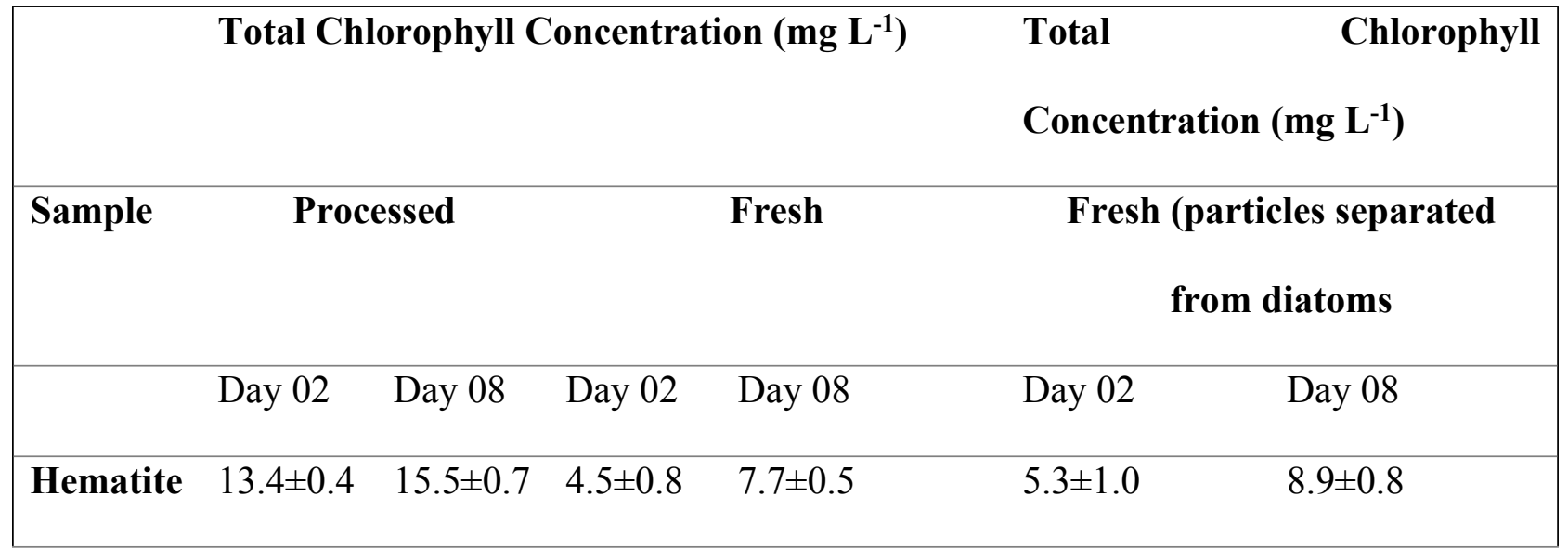




\begin{tabular}{|lcccccc|}
\hline Hematite & $14.7 \pm 0.4$ & $29.6 \pm 1.5$ & $2.8 \pm 0.6$ & $3.8 \pm 0.9$ & $5.2 \pm 0.9$ & $8.6 \pm 1.0$ \\
+ TiO$_{2}$ & & & & & \\
\hline Micro & $4.5 \pm 0.6$ & $12.4 \pm 2.7$ & $0.4 \pm 0.05$ & $9.5 \pm 1.1$ & $1.1 \pm 0.2$ & $1.6 \pm 0.2$ \\
ilmenite & & & & & & \\
\hline Nano & $2.3 \pm 0.3$ & $23.8 \pm 2.1$ & $1.5 \pm 0.3$ & $14.5 \pm 2.5$ & $3.4 \pm 0.6$ & $6.2 \pm 0.6$ \\
Ilmenite & & & & & & \\
\hline Anatase & $1.0 \pm 0.2$ & $1.0 \pm 0.2$ & $0.9 \pm 0.2$ & $0.8 \pm 0.1$ & $0.8 \pm 0.04$ & $0.2 \pm 0.07$ \\
Negative & $0.8 \pm 0.2$ & $0.8 \pm 0.2$ & $0.8 \pm 0.1$ & $0.2 \pm 0.1$ & $0.9 \pm 0.06$ & $0.2 \pm 0.03$ \\
Control & & & & & & \\
\hline
\end{tabular}




\section{Cell count changes as dust was added}

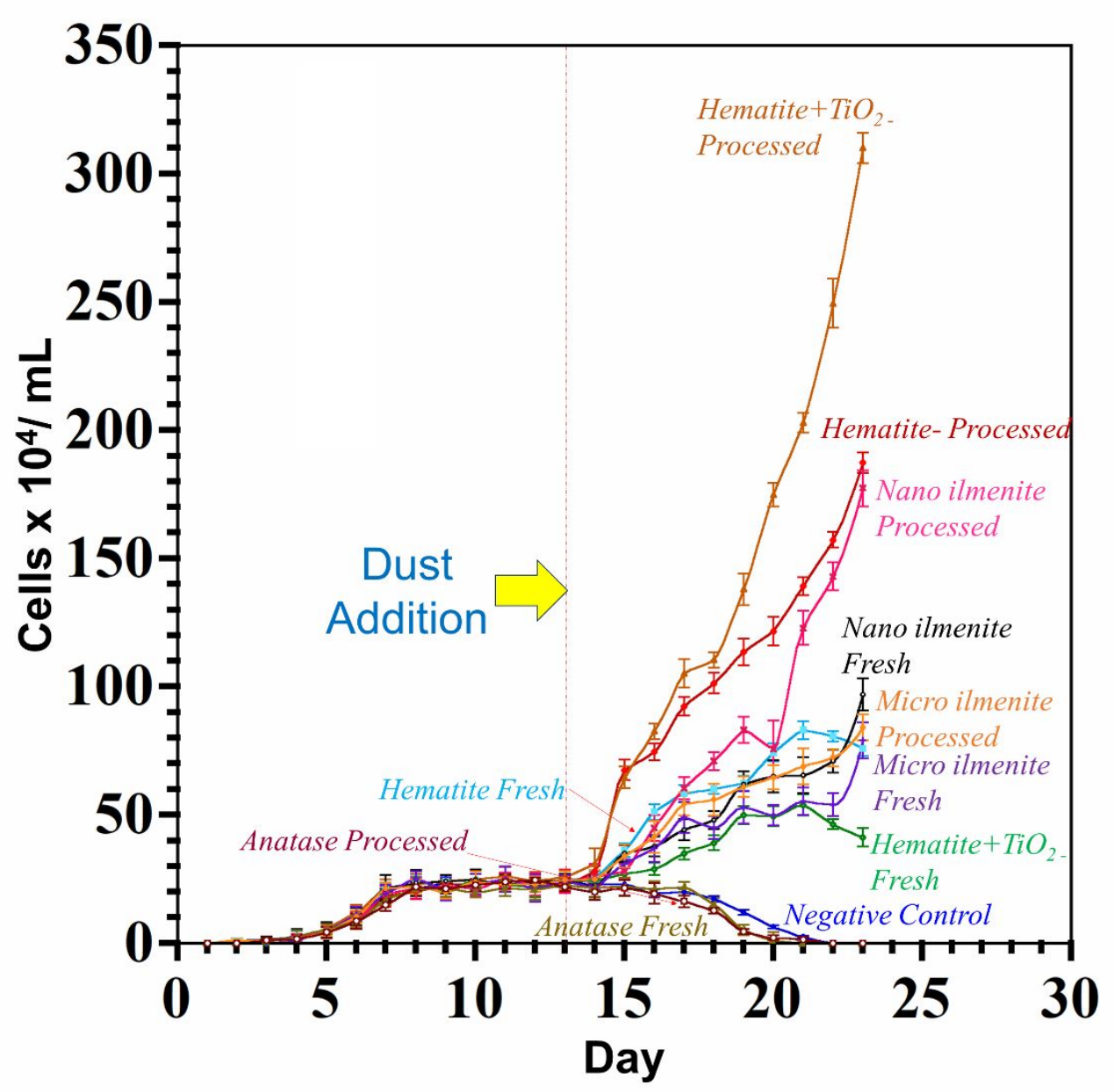

Figure S 13: Cell counts from different cultures before and after dust addition

\section{References}

(1) Hettiarachchi, E.; Hurab, O.; Rubasinghege, G. Atmospheric Processing and Iron Mobilization of Ilmenite: Iron-Containing Ternary Oxide in Mineral Dust Aerosol. J. Phys. Chem. A 2018, 122, 1291-1302. https://doi.org/10.1021/acs.jpca.7b11320.

(2) Hettiarachchi, E.; Reynolds, R. L.; Goldstein, H. L.; Moskowitz, B.; Rubasinghege, G. Bioavailable Iron Production in Airborne Mineral Dust: Controls by Chemical Composition and Solar Flux. Atmos. Environ. 2019, 205, 90-102. 
https://doi.org/10.1016/j.atmosenv.2019.02.037.

(3) Cwiertny, D. M.; Baltrusaitis, J.; Hunter, G. J.; Laskin, A.; Scherer, M. M.; Grassian, V. H. Characterization and Acid-Mobilization Study of Iron-Containing Mineral Dust Source Materials. J. Geophys. Res. Atmos. 2008, 113, 1-18. https://doi.org/10.1029/2007JD009332.

(4) Chen, H.; Grassian, V. H. Iron Dissolution of Dust Source Materials during Simulated Acidic Processing: The Effect of Sulfuric, Acetic, and Oxalic Acids. Environ. Sci. Technol. 2013, 47 (18), 10312-10321. https://doi.org/10.1021/es401285s.

(5) Fu, H.; Cwiertny, D. M.; Carmichael, G. R.; Scherer, M. M.; Grassian, V. H. Photoreductive Dissolution of Fe-Containing Mineral Dust Particles in Acidic Media. J. Geophys. Res. Atmos. 2010, 115, 1-12. https://doi.org/10.1029/2009JD012702.

(6) Rubasinghege, G.; Lentz, R. W.; Scherer, M. M.; Grassian, V. H. Simulated Atmospheric Processing of Iron Oxyhydroxide Minerals at Low PH: Roles of Particle Size and Acid Anion in Iron Dissolution. Proc. Natl. Acad. Sci. 2010, 107, 6628-6633. https://doi.org/10.1073/pnas.0910809107.

(7) Borgatta, J.; Paskavitz, A.; Kim, D.; Navea, J. G. Comparative Evaluation of Iron Leach from Different Sources of Fly Ash under Atmospherically Relevant Conditions. Environ. Chem. 2016, 13, 902-912. https://doi.org/10.1071/EN16046.

(8) Stucki, J. W. The Quantitative Assay of Minerals for Fe2+ and Fe3+ Using 1,10Phenanthroline; Sources of Variability. SOIL Sci. Soc. Am. J. 1981, 45, 638-641. https://doi.org/10.2136/sssaj1981.03615995004500030039x. 
(9) Cwiertny, D. M.; Hunter, G. J.; Pettibone, J. M.; Scherer, M. M.; Grassian, V. H. Surface Chemistry and Dissolution of \&alpha;-FeOOH Nanorods and Microrods: Environmental Implications of Size-Dependent Interactions with Oxalate. J. Phys. Chem. C 2009. https://doi.org/10.1021/jp807336t.

(10) Hettiarachchi, E.; Reynolds, R. L.; Goldstein, H. L.; Moskowitz, B.; Rubasinghege, G. Iron Dissolution and Speciation in Atmospheric Mineral Dust: Metal-Metal Synergistic and Antagonistic Effects. Atmos. Environ. 2018, 187, 417-423. https://doi.org/10.1016/j.atmosenv.2018.06.010.

(11) Hettiarachchi, E.; Rubasinghege, G. Mechanistic Study on Iron Solubility in Atmospheric Mineral Dust Aerosol: Roles of Titanium, Dissolved Oxygen, and Solar Flux in Solutions Containing Different Acid Anions. ACS Earth Sp. Chem. 2019, acsearthspacechem.9b00280. https://doi.org/10.1021/acsearthspacechem.9b00280.

(12) Al-Abadleh, H. A. Review of the Bulk and Surface Chemistry of Iron in Atmospherically Relevant Systems Containing Humic-like Substances. RSC Adv. 2015, 5 (57), 4578545811. https://doi.org/10.1039/C5RA03132J.

(13) Wu, H.; Yin, J.-J.; Wamer, W. G.; Zeng, M.; Lo, Y. M. Reactive Oxygen Species-Related Activities of Nano-Iron Metal and Nano-Iron Oxides. J. Food Drug Anal. 2014, 22 (1), 8694. https://doi.org/10.1016/j.jfda.2014.01.007. 